\title{
More guidance on growth hormone deficiency
}

\section{R Ayling}

\section{Is it needed?}

G rowth is controlled and modulated by many factors, including nutritional, environmental, and endocrine mechanisms. During the lst year of life, nutrition is the most important factor determining growth. Growth hormone (GH) is essential for growth throughout childhood, with sex steroids contributing to the pubertal growth spurt.

$\mathrm{GH}$ is released from the anterior pituitary gland under the influence of the opposing hypothalamic regulatory peptides, GH releasing hormone (GHRH) and somatostatin. The actions of GH are largely indirect, via insulinlike growth factors (IGFs), which exert negative feedback control on GH release. The GH releasing peptide ghrelin is the endogenous ligand for the $\mathrm{GH}$ secretagogue (GHS) receptor and induces a positive energy balance using an additional mechanism for GH control. It is produced predominantly by the stomach and appears to have a role in the integration of energy balance and growth.

\section{GH DEFICIENCY}

GH deficiency (GHD) leads to a reduction in the generation of GH dependent factors, particularly IGF-I and its major binding protein IGF binding protein 3 (IGFBP3), which has auxological, clinical, and biochemical sequelae. Children with GHD are eligible for treatment with recombinant GH but their definition remains difficult. This difficulty in definition is reflected by the variability in prevalence in GHD from 287/million in the USA, to 20/million in the UK, and by the large proportion of children diagnosed who are subsequently found to have normal GH secretion unless strict auxological and biochemical criteria are used for diagnosis. ${ }^{1}$ Short stature may be the presenting feature of GHD, characteristically after a period of normal growth, yet the definition of short stature can itself be difficult.

\section{Assessment of GHD}

Assessment of an individual child's growth requires information regarding the limits of normal variability, which can be obtained by plotting the height and height velocity on relevant curves derived from cross sectional and longitudinal data. By comparison with parental height centiles, it can be determined whether the child is growing appropriately for the family. Measurement of the skeletal age ${ }^{2}$ allows an estimation of the extent of future growth. The selection of children for GH treatment based solely on auxological criteria has been used in Australia. ${ }^{4}$ However, physiological interindividual variations in growth rate may make this an unreliable means of assessment $^{5}$ and, in addition, a normal growth velocity can, in specific clinical circumstances, be associated with GHD. ${ }^{6}$ A further problem with the use of auxological data is that curve fit is poor at the outer centiles of the curves, where the least number of data points is available, and the charts themselves do not cover the range below the 0.4th centile, making their use in very short children inappropriate.

\section{"Children with growth hormone deficiency are eligible for treatment with recombinant growth hormone but their definition remains difficult"}

Imaging of the hypothalamo-pituitary region by computed tomography or magnetic resonance imaging scanning forms an important part of the investigation of children with GHD. ${ }^{7}$ It is performed to rule out tumours, particularly craniopharyngiomas, and to look for structural abnormalities that could be associated with GHD. Structural abnormalities can be developmental defects or lesions acquired as a result of trauma, treatment, or infiltrative conditions.

Components of the hypothalamopituitary-IGF axis have been investigated as candidates for use in the diagnosis of GHD. The secretion of GH from the pituitary is pulsatile, with most surges occurring during sleep. Between pulses, plasma concentrations of $\mathrm{GH}$ are low, making random sampling of little use in the diagnosis of $\mathrm{GHD}^{8}{ }^{8}$ except in neonates, where the pulses are of higher amplitude and frequency. ${ }^{9}$ Studies of pulsatile GH secretion can be performed by serial sampling every 20-30 minutes, either overnight or for 24 hours, GH secretion being expressed in various ways according to the concentrations obtained from multiple sampling. The reproducibility of such tests has been found to be poor, although better than that of stimulation tests, ${ }^{10}$ and normally growing children may have low concentrations. ${ }^{11}$ Because admission to hospital is required and the test protocols are complicated, such tests tend to be carried out only in specialists units.

The development of sensitive assays for the low concentrations of $\mathrm{GH}$ present in urine has encouraged its use as a marker of GHD. However, there is overlap in urinary $\mathrm{GH}$ concentrations between normal children and those with GHD, and the test cannot be used reliably to discriminate between them. ${ }^{12}$

Because of their close association with GH, plasma IGF and IGFBP concentrations have been investigated as markers of GHD. ${ }^{13} 14$ IGF-I cannot be used in infants and is of limited use in younger children because of its physiologically low concentrations. Intercurrent illness and malnutrition can also lower IGF concentrations. Assuming that these factors have been considered, an IGF-I concentration $<2$ SD suggests a defect within the $\mathrm{GH}$ axis.

\section{GH stimulation tests}

The lack of a suitable replacement has led to the continued use of GH stimulation tests, although they are non-physiological and not without risk. ${ }^{15}$ There is no "gold standard" test, more than 34 having been described, the most frequently cited being clonidine, insulin induced hypoglycaemia, arginine, glucagon, and GHRH.

There are several fundamental problems with GH stimulation tests. The $\mathrm{GH}$ response used to define deficiency relies on arbitrary cutoff points, there are limited data available in children with normal height velocity, and the tests have poor reproducibility. In addition, the use of stimulation tests is further complicated by inherent problems with GH assays. Hence, the results of two stimulation tests are usually considered when making a diagnosis of GHD.

There is no clear definition of what constitutes a normal rise in plasma GH after stimulation. Because GH secretion would be expected to cover a spectrum-from absolute deficiency, through insufficiency, to normal-any definition applied would be arbitrary, and might be expected to show overlap between normal children and those 
with GHD. The cutoff value for the diagnosis of GHD has increased in the past 40 years from $10 \mathrm{mU} /$ litre $^{16}$ in 1968 , to $15 \mathrm{mU} /$ litre $^{17}$ in 1974 , to $20 \mathrm{mU} /$ litre $^{18}$ in 1995. During this time methodology for measuring GH has changed.

Radioimmunoassays have been replaced by two site immunoradiometric assays, which in some places have been superseded by automated non-isotopic methods. The newer assays can give GH concentrations two to three times lower than older radioimmunoassays, ${ }^{19}$ yet the cutoff value has not been correspondingly decreased. There are limited data from GH stimulation tests in normal children, but those that are available from children with normal growth velocities show that the reproducibility of standard stimulation tests is poor, and that they frequently fail to increase the GH concentration above conventional cutoffs, indicating that a single test is insufficient for the diagnosis of GHD. $^{2021}$ The interpretation of the GH response to stimulation is further complicated because there is variation in secretion with age and pubertal stage. It has been suggested that priming with sex steroids could ensure an adequate GH response to stimulation in healthy prepubertal children. ${ }^{22}$ Inconsistencies in their use further complicate the interpretation of clinical studies of the $\mathrm{GH}$ response. There is no consensus as to whether sex steroid priming should be used to augment the $\mathrm{GH}$ response in prepubertal children. ${ }^{7} \mathrm{GH}$ secretagogues such as GHRP6 and hexarelin have been shown to stimulate GH secretion. ${ }^{23}$ These substances may have a role to play in provocation testing in the future, but age related variability in response to currently available agents may limit their usefulness.

\section{"The lack of a suitable replacement has led to the continued use of growth hormone stimulation tests, although they are non-physiological and not without risk"}

Difficulties with the interpretation of stimulation tests are exacerbated by problems with the assay of GH resulting from its molecular diversity. GH is a polypeptide hormone, with $90 \%$ of that formed in the pituitary being a $22 \mathrm{kDa}$ form composed of 191 amino acid residues. The remainder is a $20 \mathrm{kDa}$ form of 176 residues arising from an alternative splice site at exon 3. Within the circulation there are other forms resulting from post translational modification, metabolic degradation, and association with GH binding protein. Differences in assay bias can, in part, be explained by the ability of the system to detect $20 \mathrm{kDa}$ human GH, with assays using monoclonal antibodies for capture and detection tending to show less crossreactivity than monoclonal/polyclonal pairs. It has been recommended that $\mathrm{GH}$ assays should recognise only $22 \mathrm{kDa}$ $\mathrm{GH} .{ }^{24}$ Although leading to uniformity, this would result in loss of clinical information about bioactive GH. Bias differences between methods could be reduced by the introduction of a common calibrant, ${ }^{25}$ and the use of the new IS $88 / 624$, calibrated in mass units of $22 \mathrm{kDa}$ human $\mathrm{GH}$, has been put forward.

\section{The need for further guidance in GHD testing}

More than 6000 papers have been written on biochemical testing in GHD and paediatricians and clinical biochemists should be aware that it is a controversial subject. In this issue of the Journal of Clinical Pathology, Evans and Gregory ${ }^{26}$ present the results of a survey of the investigation of short stature in Wales and suggest guidelines to improve practice. Various consensus documents dealing with the diagnosis of GHD have already been produced, ${ }^{7}{ }^{27-32}$ including that from the GH Research Society, which gives clear guidelines for both diagnosis and treatment of GHD. One might ask whether further guidance is needed; the results of the Welsh survey suggest that it is. Evans and Gregory examined the results of questionnaires sent to paediatricians and clinical biochemists in all 13 hospitals in Wales involved in the investigation of children with short stature. They showed evidence of failure to complete clinical evaluation before starting investigation and lack of defined investigative protocols. There was a lack of agreement between paediatricians and clinical biochemists with regard to the tests in use, how they should be performed, and the interpretation of their results. Although GH was measured in four laboratories, using two assays, nine different cutoff values were quoted to define GHD-with paediatricians and clinical biochemists offering different cutoffs in three centres. The origin of the cutoff values was stated to be unknown, unspecified, uncertain $(\mathrm{n}=16)$, or from published work more than 15 years old $(n=8)$. These findings are not unexpected. A recent survey in Europe showed large heterogeneity in both clinical and laboratory aspects of the diagnosis of GHD, particularly with regard to the standardisation of assays and the interpretation of cutoff values. ${ }^{33}$ Previous audits have shown that cutoffs used in the interpretation of GH stimulation tests are not always related to method bias. ${ }^{34} 35$
The diagnosis of GHD is an important one, which has considerable resource implications, is relatively arduous, and potentially dangerous. ${ }^{36} \mathrm{~A}$ recent systematic review concluded that it was not possible to recommend biochemical tests of GH function in children or offer advice on their interpretation. ${ }^{37}$ However in the UK, the National Institute for Clinical Excellence (NICE) recommends treatment with recombinant human GH for children with GHD supported by auxological, biochemical, and radiological investigations, ${ }^{38}$ so at present biochemical investigation of GHD in children is necessary before the initiation of treatment.

"The diagnosis of growth hormone deficiency is an important one, which has considerable resource implications, is relatively arduous, and potentially dangerous"

Although guidelines may not be wholly applicable outside the unit in which they were written, and may require flexibility in their application to individual patients, those proposed here cover the initial investigation of short stature, provocation testing, and retesting after attainment of final height, and could certainly make a useful contribution to practising within the NICE framework.

J Clin Pathol 2004:57:123-125.

doi: 10.1136/jcp.2003.8029

Correspondence to: Dr R Ayling, Department of Clinical Chemistry, Derriford Hospital, Plymouth, Devon PL6 8DH, UK; ruthayling@clinicalbiochemistry.org.uk

\section{REFERENCES}

1 Guyda HJ. Growth hormone testing and the short child Pediatr Res 2000:48:579-80.

2 Greulich WW, Pyle SI. Radiographic atlas of skeletal development of the hand and wrist, 2nd ed. Stanford, USA: Stanford University Press, 1959

3 Tanner JM, Whitehouse RH, Cameron N, et al. Assessment of skeletal maturity and prediction of adult height (TW2 method). New York: Academic Press, 1983

4 Werther GA. Growth hormone measurements versus auxology in treatment decisions; the Australian experience. J Pediatr 1996; 128:S47-51.

5 Voss LD, Bailey BJR, Cumming K, et al. The reliability of height measurement (the Wessex growth study). Arch Dis Child 1990;65:1340-4.

6 Gluckman PD. Growth hormone deficiency diagnosed and treated during the first two years of life: evidence for the role of growth hormone in human perinatal growth. In: Ranke MB, Gunnarsson R, eds. Progress in growth hormone therapy -5 years of KIGS. Mannheim: J\&J Verlag, 1994:88-96.

7 GH Research Society. Consensus guidelines for the diagnosis and treatment of growth hormone (GH) deficiency in childhood and adolescence: summary statement of the GH Research Society. I Clin Endocrinol Metab 2000:85:3990-3.

8 Albertsson-Wikland K, Rosberg S. Analyses of 24-hour growth hormone $(\mathrm{GH})$ profiles in 
children: relation to growth. J Clin Endocrinol Metab 1988;67:493-500.

9 Adcock CJ, Ogilvy-Stuart AL, Robinson IC, et al. The use of an automated microsampling system for the characterization of growth hormone pulsatility in newborn babies. Pediatr Res 1997:42:66-71.

10 Tassoni P, Cacciari E, Cau M, et al. Variability of growth hormone response to pharmacological and sleep tests performed twice in short children. J Clin Endocrinol Metab 1990;71:230-4.

11 Lanes R. Diagnostic limitations of spontaneous growth hormone measurements in normally growing prepubertal children. Am J Dis Child 1989;143:1284-6.

12 Georges P, Liefooghe J, Ponchaux D, et al. Urinary growth hormone excretion: results of a multicentre study in France. Horm Res 1997;47:30-7.

13 Moore DC, Ruvalcaba RH, Smith EK, et al. Plasma somatomedin-C as a screening test for growth hormone deficiency in children and adolescents. Horm Res 1982;16:49-55.

14 Ranke MB, Schweizer R, Elmlinger MW, et al. Significance of basal IGF-I, IGFBP-3 and IGFBP-2 measurements in the diagnostics of short stature in children. Horm Res 2000;54:60-8.

15 Shah A, Stanhope R, Matthew D. Hazards of pharmacological tests of growth hormone secretion in childhood. BMJ 1992;304:173-4.

16 Kaplan SL, Abrams CA, Bell JJ, et al. Growth and growth hormone. Changes in serum level of growth hormone following hypoglycaemia in 134 children with growth retardation. Pediatr Res 1968:2:43-63.

17 Frasier SD. A review of growth hormone stimulation tests in children. Pediatrics 1974:53:929-37.

18 Guidelines for the use of growth hormone in children with short stature: a report of the drugs and therapeutics committee of the Lawson Wilkins
Pediatric Endocrine Society. J Pediatr 1995; 127:857-67.

19 Celniker $A C$, Chen $A B$, Wert $A B$ Jr. Variability in the quantitation of circulating growth hormone using commercial immunoassay. J Clin Endocrinol Metab 1989;68:469-76.

20 Zadik Z, Chalew S, Kowarski A. Assessment of growth hormone secretion in normal stature children using 24 hour integrated concentrations of $\mathrm{GH}$ and pharmacological stimuli. J Endocrino Metab 1990;71:932-6.

21 Ghigo E, Bellone J, Aimaretti G, et al. Reliability of provocation tests to assess growth hormone secretory status. Study in $\mathbf{4 7 2}$ normally growing children. J Endocrinol Metab 1996;81:3323-7.

22 Marin G, Domene HM, Barnes KM, et al. The effect of estrogen priming in puberty on the growth hormone response to standardised treadmill exercise and arginine-insulin in normal boys and girls. J Clin Endocrinol Metab 1994;79:537-41.

23 Loche S, Cambiaso P, Carta D, et al. The growth hormone-releasing activity of hexarelin, a new synthetic hexapeptide, in short normal and obese children, and in hypopituitary subjects. J Clin Endocrinol Metab 1995;80:674-8.

24 Ranke M, Orskov H, Bristow AF, et al. Consensus on how to measure growth hormone in serum. Horm Res 1999;51:S27-9.

25 Wood P. Growth hormone: its measurement and the need for assay harmonization. Ann Clin Biochem $2001 ; 38: 471-82$.

26 Evans C, Gregory JW. The investigation of short stature: a survey of practice in Wales and suggested practical guidelines. J Clin Pathol 2004;57:126-30.

27 Round table discussion. The rational approach in the diagnosis of human growth hormone deficiency; partial and transitory hGH deficiency. Pediatric and Adolescent Endocrinology 1983; 12:122-32.
28 Rosenfeld RG, Albertsson-Wilkland K, Cassorla F, et al. Diagnostic controversy: the diagnosis of childhood growth hormone deficiency revisited. J Clin Endocrinol Metab 1995:80:1532-40.

29 Hindmarsh PC, Swift PG. An assessment of growth hormone provocation tests. Arch Dis Child 1995;72:362-7.

30 Hunter MK, Rosenfeld RG. Can we diagnose growth hormone deficiency? Current Opinion in Endocrinology and Diabetes 1996;3:83-7.

31 Shalet SM, Toogood A, Rahim A, et al. The diagnosis of growth hormone deficiency in children and adults. Endocr Rev 1998; 19:203-23.

32 Saggese G, Ranke MB, Saenger P, et al. Diagnosis and treatment of growth hormone deficiency in children and adolescents: towards a consensus. Horm Res 1998:50:320-40.

33 Juul A, Bernasconi S, Clayton PE, et al. European audit of current practice in diagnosis and treatment of childhood growth hormone deficiency. Horm Res 2002;58:233-41.

34 Seth J, Ellis A, Al-Sadie R. Serum growth hormone measurements in clinical practice: an audit of performance from the UK National External Quality Assurance Scheme. Horm Res 1999:51(suppl 1):13-19.

35 Ellis A, Seth J, Al-Sadie R, et al. An audit of the laboratory interpretation of growth hormone response to insulin-induced hypoglycaemia in the assessment of short stature in children. Ann Clin Biochem 2003:40:239-43.

36 Clayton PE, Cowell CT. Safety issues in children and adolescents during growth hormone therapy-a review. Growth Horm IGF Res 2000;10:306-17.

37 Butler J. Biochemical tests of growth hormone status in short children. Ann Clin Biochem 2001;38:1-2.

38 National Institute for Clinical Excellence. Guidance on the use of human growth hormone (somatotropin) in children with growth failure. Technological appraisal guidance, No 42, 2002 